\title{
STATUS OF A $\rightarrow$ T POLYMORPHISM IN EXON II OF KINASE INSERT DOMAIN GENE IN WOMEN WITH PREMATURE OVARIAN FAILURE
}

\author{
Available online at www.ijdra.com \\ RESEARCH ARTICLE \\ ${ }^{1}$ RGB Ali H. Hasan*, ${ }^{2}$ Sujatha M. \\ ${ }^{1}$ Research Scholar, Dept. of Biotechnology, Institute of Science \& Technology, JNTU, Hyderabad, \\ India. \\ ${ }^{2}$ Dept. of Clinical Genetic, Institute of Genetics and Hospital for Genetic Diseases, Osmania \\ University, Hyderabad, India. \\ *Corresponding Author's E-mail: haideralwageehy85@yahoo.com
}

\begin{abstract}
Ovarian failure is defined as cessation of ovarian function under the age of 40 and it is characterized by amenorrhea hypo estrogenism and elevated gonadotrophin serum levels leading to infertility. Ovarian failure affects $1 \%$ of women. Causes of ovarian failure are extremely heterogenous. Ovarian failure is caused either by accelerated loss of eggs or the follicles themselves become less responsive to hormonal stimulation. It is high levels of gonadotrophins (luteinizing hormone and follicle stimulating hormone) hormonal defects may cause severe cardio vascular consequences and leads to the early onset of osteoporosis. Vascular endothelial growth factor (VEGF) is a major growth factor for endothelial cells. VEGF is involved in the process of angiogenesis for the development of Graffian follicle an important feature of growing follicle which has been arrested in the primordial follicular stage .VEGF mediates the process of angiogenesis through its receptors I and II.. Receptor II is known as Kinase insert domain receptor, is a type III receptor tyrosine Kinase.KDR is located at $4 \mathrm{q} 11-\mathrm{q} 12$. The main objective of this study was to screen the mutations in Kinase insert domain by using the techniques DNA isolation, Polymerase chain reaction and restriction fragment length polymorphism.
\end{abstract}

Keywords: Estrogenism; Gonadotrophin; PCR, RFLP, Polymorphism; KDR, Vascular endothelial growth factor (VEGF)..

\section{INTRODUCTION}

embryogenesis, organ development, estrus, and wound healing require vascular growth and remodeling. $(1,2)$ In addition to these beneficial processes, angiogenesis is also involved in the proliferation of disease states such as tumor growth, metastasis, psoriasis, rheumatoid arthritis, macular degeneration and retinopathy. (3-7) Of the signaling pathways known to influence vascular formation, that involving vascular endothelial growth factor (VEGF) has been shown to be essential and selective for vascular endothelial cells. (8-10) The therapeutic potential of inhibiting the VEGF pathway has been directly demonstrated by antiVEGF monoclonal antibodies, which are active against a variety of human tumors (11) and ischemic retinal disease. (12) The bodies of females and males are alike in many ways, but their reproductive systems are quite different. Like nearly every living organism, two genders- female and male-are needed for reproduction. (13) KINASE INSERT DOMAIN. The official name of this gene is "Kinase insert domain receptor (a type III receptor tyrosine Kinase). $\mathrm{KDR}$ is the gene's official symbol.

Vascular endothelial growth factor (VEGF) is a major growth factor for endothelial cells. This gene encodes one of the two receptors of the VEGF. This receptor, known as Kinase insert domain receptor, is a type III receptor tyrosine Kinase. It functions as the main mediator of VEGF-induced endo-thelial proliferation, survival, migration, tubular morphogenesis and sprouting. The signalling and trafficking of this receptor are regulated by multiple factors, including Rab GTPase, P2Y purine nucleotide receptor, integrin alphaVbeta3, T-cell protein tyrosine phosphatase, etc.. Mutations of this gene are implicated in infantile capillary hemangiomas. (14) 
VEGF is a homodimeric cytokine that is expressed in at least four splice-variant forms of 121-206 residues. (15) Vascular endothelial cells express at least two high-affinity receptors for VEGF: VEGFR1 (also referred to in the literature as Flt-1) and VEGFR2 (also referred to as $\mathrm{KDR}$ ). Another related receptor, VEGFR3/Flt-4, binds the VEGF-like growth factor,VEGF-C, believed to function in lymphogenesis. (16) These VEGFRs are receptor tyrosine Kinases each comprised of an extracellular domain that binds VEGF and contains seven immunoglobulin-like segments, a short membrane spanning region, and a cytosolic domain possessing tyrosine-Kinase activity. The Kinase domain directly follows the extracellular and juxta membrane regions and is itself followed by another domain (referred to here as the post-Kinase domain), which may function in binding of other proteins for signal transduction. VEGFR1 and VEGFR2 appear to have different signaling pathways and functions, with VEGFR2 being of primary importance in mitosis of endothelial cells (1719).

\section{MATERIALS AND METHODS}

15 blood samples were collected from the women affected with ovarian failure and 15 samples with age matched and with history of ovarian failure were taken as control.

\section{Isolation of DNA and Genotyping}

The blood was collected in EDTA tubes. Genomic DNA was extracted from blood samples using standard phenol chloroform method.

\section{ESTIMATION OF DNA}

By check the absorbance ratio, it should be between the readings at A260 $\mathrm{nm} \&$ A280 nm. The KID receptor gene was analysed by polymerase chain reaction-restriction fragment length polymer-phism technique. The primers used for the amplification of the KID receptor gene are Forward Primer: 5'TTTTTGTCCCCATA GTAACA-3 'Reverse: 5'-AATGAGGG ACCACAGCA-3', The amplified 382 bp PCR product was digested with AluI enzyme it which yields three bands 220, 104, 58 base pair (normal sequence), if it is heterozygous the product yields the four separate bands of 278,220,104 and 58 base pair and if there is mutation it yields two separate bands of 278 and 104 base pair.

\section{Detection of PCR Product by Agarose Gel Electrophoresis}

The PCR products should be fragments of DNA of defined length, the simplest way to check for the presence of the fragments is to load a sample taken from the reaction product, along with the appropriate molecular weight markers, on to an $2 \%$ agarose gel which contains $0.8-4.0 \%$ Ethidium Bromide. DNA bands on the gel can then be visualized under UV gel doc. By comparing product bands with bands from the know molecular weight markers, we should be able to identify any product fragments, which are of appropriate molecular weight.

\section{RESULTS}

We screened 15 samples of the patients affected with ovarian failure along with 15 similar number of healthy controls with no prior medical history were taken as controls. The patient samples were designated with alphabet "s" and numbered accordingly. While, The controls samples were designated with alphabet "c" and numbered accordingly. These samples were subjected to PCR-RFLP analysis, the Kinase insert domain gene exon 11 was amplified to yield a single band of $382 \mathrm{bp}$ on agarose gel electrophoresis this product was then subjected to the restriction digestion using AluI enzyme. Our result revealed that the individuals has no polymorphism in Kinase insert domain exon 11 fragement.

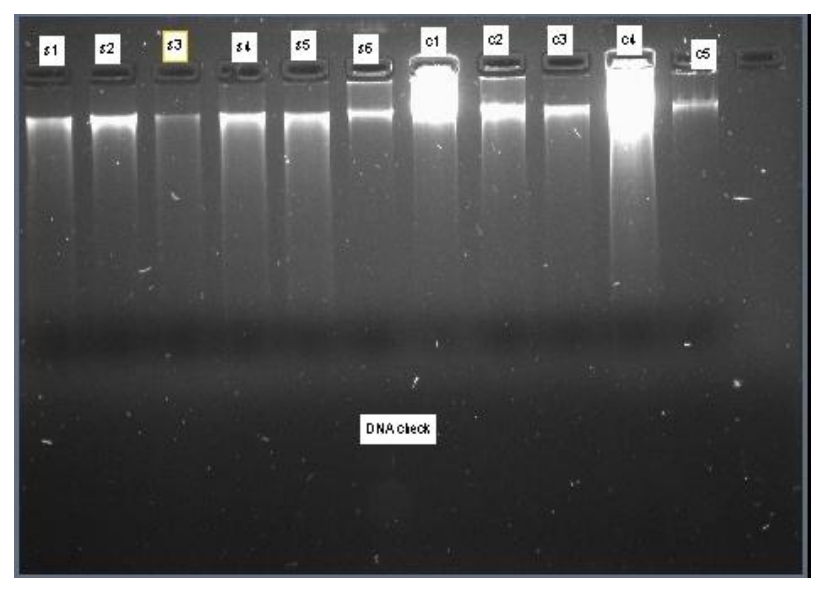

Figure 1: Gel picture showing Genomic DNA 


\begin{tabular}{|l|l|}
\hline LANE 1: Sample S1 & LANE 7: Control C1 \\
\hline LANE 2: Sample S2 & LANE 8: Control C2 \\
\hline LANE 3: Sample S3 & LANE 9: Control C3 \\
\hline LANE 4: Sample S4 & $\begin{array}{l}\text { LANE 10: Control } \\
\text { C4 }\end{array}$ \\
\hline LANE 5: Sample S5 & $\begin{array}{l}\text { LANE 11: Control } \\
\text { C5 }\end{array}$ \\
\hline LANE 6:sample S6 & \\
\hline
\end{tabular}

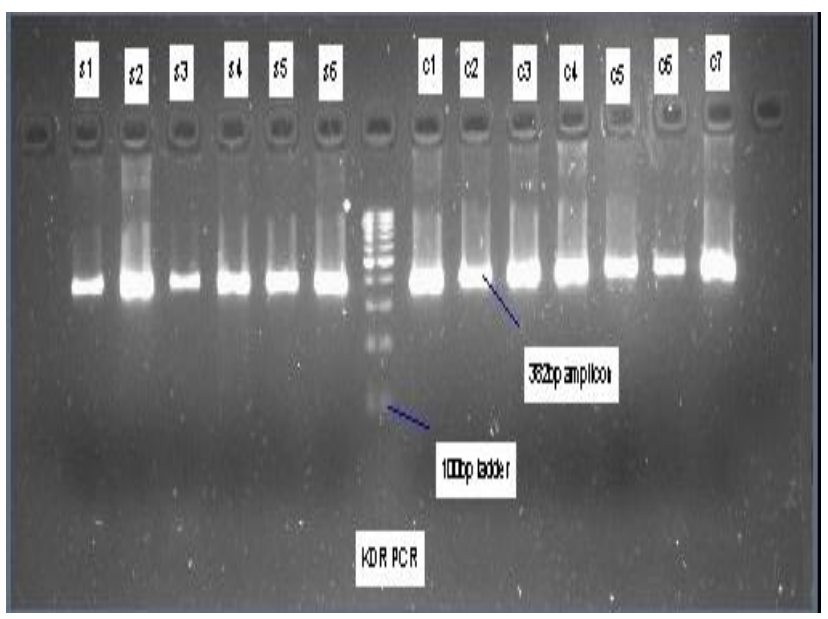

Figure 2: Gel Picture showing PCR Samples

\begin{tabular}{|l|l|}
\hline LANE 1: Sample S1 & LANE 8: Control C1 \\
\hline LANE 2: Sample S2 & LANE 9: Control C2 \\
\hline LANE 3: Sample S3 & LANE 10: Control C3 \\
\hline LANE 4: Sample S4 & LANE 11: Control C4 \\
\hline LANE 5: Sample S5 & LANE 12: Control C5 \\
\hline LANE 6: Sample S6 & LANE13: Control C6 \\
\hline $\begin{array}{l}\text { LANE7: 100 bp } \\
\text { ladder }\end{array}$ & LANE 14: Control C7 \\
\hline
\end{tabular}

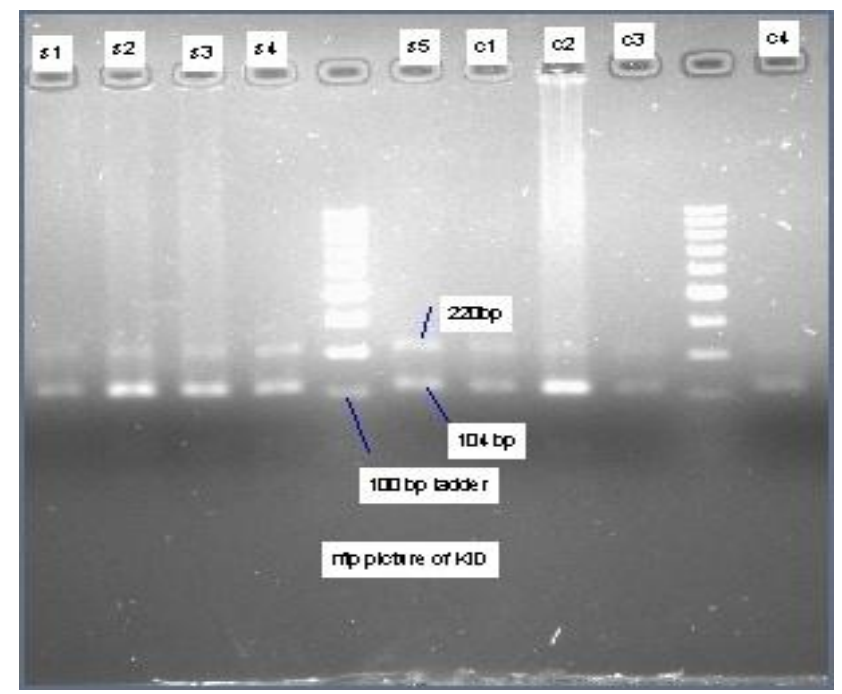

Figure 3: Gel Picture showing RFLP products

\begin{tabular}{|l|l|}
\hline LANE 1: Sample S1 & LANE 6: Control C1 \\
\hline LANE 2: Sample S2 & LANE 7: Control C2 \\
\hline LANE 3: Sample S3 & LANE 8: Control C3 \\
\hline LANE 4: Sample S4 & $\begin{array}{l}\text { LANE 9:100 bp } \\
\text { DNA ladder }\end{array}$ \\
\hline $\begin{array}{l}\text { LANE 5: 100 bp } \\
\text { DNA ladder }\end{array}$ & $\begin{array}{l}\text { LANE 10: Control } \\
\text { C4 }\end{array}$ \\
\hline
\end{tabular}

\section{DISCUSSION}

To assess the occurrence of prematire ovarian failure, the age-specific incidence rates of natural menopause were determined for a cohort of 1858 women born between 1928 and 1932 . These women were identified as rochester, minnesota residents in 1950 and were followed for date and type of menopause. A total of experienced natural menopause before age 40 years, which represents a $1 \%$ risk of natural menopause to age 40 .The annual incidence rates of natural menopause per 100000 person years were 10 for age 15 to 29 and 76 for ages 30 to 39 .In the age group 40 to 44 , the incidence of natural menopause increased greatly to 881 per 100000 person- year at risk.

Mutations which are identified in $\mathrm{X}$ chromosomes gene are FMR1, FMR2, BMP15. Mutation which are identified in autosomal gene are FOXL2, FSHR, LH receptor, FSH beta variant, LH beta, GALT, AIRE, NOGGIN, POLG, Inhibin A. Candidate genes are observed in $\mathrm{X}$ chromosome are DIAPH2, DFFRX, XPNPEP2, ZFX, XIST. Candidate gene which are observed in autosomal genes are WTI, ATM. Mutation which are not identified in $\mathrm{X}$ chromosome genes are AT2,SOX3,C-KIT. Mutations which are not identified in autosomal gene are MIS.

Angeogenesis is an important property of ovarian follicular development in which a primodial follicle which has been arrested during embryogenesis develops into a graphian follicle which is ready to release the egg by different action of enzyme. Studies have been shown those angeogenesis factors are more expressed to facilitate the development of the follicle. Any mutation in angeogenesis receptor may lead to ovarian failure. 
In these study 15 cases with ovarian failure and 15 age and sex matched healthy controls were screened for the detection of A-T at nucleotide 1719 in Kinase insert domain receport exon 11. Blood samples from these cases were collected genomic DNA was isolated. An RFLP analysis of segment exon11 in KID receptor was amplified by PCR, which yield a single band of 382 Base pair on agarose gel electrophoresis. This product was then subjected to restriction digestion it which yields three bands 220,104,58 base pair (normal sequence), if it is heterozygous the product yields the four separate bands of $278,220,104$ and 58 base pair and if there is mutation it yields two separate bands of 278 and 104 base pair.

\section{CONCLUSION}

The overall results of the present investigation revealed that there was no variant detectable at exon11 1719A-T position in KID receptor gene in all the cases which include 15 individual with ovarian failure and 15 age sex matched healthy controls. This study has some statistical limitations; large scale studies are required for the confirmation of the role of KID receptor gene in individuals with ovarian failure individuals. In this pilot study the results did not reveal the presence of the variant in selected individuals. However a large sample size is required for the confirmation of the role of KDR in individuals with ovarian failure.

\section{ACKNOWLEDGEMENTS}

I take this opportunity to express my deep sense of gratitude to Institute of Genetic and Hospital for Genetic Diseases, and IJDRA Publishing group for publishing our Article.

\section{CONFLICT OF INTEREST}

The authors report that there are no conflict of interest.

\section{REFERENCES}

1. Folkman J, Shing Y, Angiogenesis J. Biol. Chem, 267. 1992; p. 10931-34.

2. Risau W. Differentiation of endothelium, Faseb J. 1995; 9: 926-33.

3. Pepper MS. Positive and negative regulation of angiogenesis: From cell biology to the clinic, Vasc. Med.;1996.p. 259-66.
4. Kuiper RAJ, Schellens JHM, Blijham GH, Beijnen JH, Voest EE. Clinical research on antiangiogenic therapy. Pharma-col. Res. 1998; 37: 1-16.

5. Kumar R, Fidler IJ. Angiogenic molecules and cancer metastasis, In Vivo; 1998. p. 27-34.

6. Szekanecz Z, Szegedi G, Koch AE. Angiogenesis in rheumatoid arthritis: Pathogenic and clinical significance. J. Investig. Med. 1998; 46: 27-41.

7. Tolentino MJ, Adamis AP. Angiogenic factors in the development of diabetic iris neovascularization and retinopathy; Int. Ophthalmol. Clin. 1998; 38: 77-94.

8. Dvorak HF, Brown LF, Detmar M, Dvorak AM. Vascular permeability factor/ vascular endothelial growth factor, microvascular hyperpermeability, and angiogenesis. Am. J. Pathol. 1995; 146: 1029-39.

9. Thomas KA. Vascular endothelial growth factor, a potent and selective angiogenic agent; Cell. 1996; 271: 603-6.

10. Ferrara N, Davis-Smyth T. The biology of vascular endothelial growth factor Endocrine Rev.1997; 18: 425 .

11. Borgström P, Hillan KJ, Sriranarao P, Ferrara N. Complete inhibition of angiogenesis and growth of microtumors by anti-vascular endothelial growth factor neutralizing antibodies. Novel concepts of angiostatic therapy from intravital videomicro-scopy. Cancer Res. 1996; 56: 4032-39.

12. Adamis AP, Miller JW, et al. Inhibition of VEGF prevents retinal ischemia-associated iris neovascularization in a primate; Arch. Ophthalmol. 1996;114:66-71.

13. Reproductive system, lorrie klosterman . p. 5,6.

14. provided by RefSeq, NCBI Gene; 2009 May.

15. Ferrara N, Davis-Smyth T. The biology of vascular endothelial growth factor. Endocrine Rev. 1997; 18: 4-25.

16. Jeltsch M, Alitalo K, et al. Hyperplasia of lymphatic vessels in VEGF-C transgenic mice. Science. 1997; 276:1423-25

17. Waltenberger J, Claesson-Welsh L, Siegbahn A, Shibuya M, Heldin CH. Different signal transduction properties of KDR and Flt1, two receptors for vascular endothelial growth factor. J. Biol. Chem. 1994; 269: 26988-95.

18. Seetharam L, Gotoh N, Maru Y, Neufeld G, Yamaguchi S, Shibuya M. A unique signal transduction pathway for the FLT tyrosine Kinase, a receptor for vascular endothelial growth factor, Oncogene. 1995; 10:135-47.

19. Shalaby F, Rossant J, Gertsenstein M, Wu XF, Breitman ML, Schuh AC. Failure of blood island formation and vasculogenesis in Flk-1 deficient mice. Nature. 1995; 376: 576-9 